NICOLA TOMMASINI

\title{
A Presunção de Constitucionalidade e In- constitucionalidade das Leis
}

\author{
Dissertação de Mestrado \\ Orientador: Prof. Dr. José Levi Mello do Amaral Júnior
}

UNIVERSIDADE DE SÃo PAulo

FACULDADE DE DIREITO

SÃo PAUlo - SP

2018 



\section{A Presunção de Constitucionalidade e In- constitucionalidade das Leis}

Dissertação de Mestrado apresentada à Banca Examinadora do Programa de PósGraduação em Direito da Universidade de São Paulo, como exigência parcial para obtenção do título de Mestre em Direito, na área de concentração de Direito do Estado, sob a orientação do Prof. Dr. José Levi Mello do Amaral Júnior.

UNIVERSIDAdE DE SÃo PAULO

FACULDADE DE DIREITO

SÃo PAUlo - SP

2018 
Serviço de Processos Técnicos da Biblioteca da Faculdade de Direito da Universidade de São Paulo

Tommasini, Nicola

A Presunção de Constitucionalidade e Inconstitucionalidade Das Leis / Nicola Tommasini - São Paulo: USP / Faculdade de Direito, 2018.

$120 \mathrm{p}$.

Dissertação (Mestrado) - Programa de Pós-Graduação em Direito, Faculdade de Direito, Universidade de São Paulo, São Paulo, 2018.

Orientador: Prof. Dr. José Levi Mello do Amaral Júnior

Notas de rodapé.

Inclui bibliografia

1. Presunção de constitucionalidade. 2. Presunção de inconstitucionalidade. 3. Autocontenção. 4. Ativismo. 5. Deferência I. Amaral Júnior, José Levi Mello do. II. Título. 
Nome: TOMMASINI, Nicola

Título: A presunção de constitucionalidade e inconstitucionalidade das leis

Dissertação de Mestrado apresentada à Banca Examinadora do Programa de Pós-Graduação em Direito da Universidade de São Paulo, como exigência parcial para obtenção do título de Mestre em Direito, na área de concentração de Direito do Estado, sob a orientação do Prof. Dr. José Levi Mello do Amaral Júnior

\section{BANCA EXAMINADORA}

Prof.: Instituição:

Julgamento: Assinatura:

Prof.: Instituição:

Julgamento: Assinatura:

Prof.: Instituição:

Julgamento: Assinatura:

Prof.: Instituição:

Julgamento: Assinatura: 



\section{RESUMO}

TOMMASINI, Nicola. A Presunção de Constitucionalidade e Inconstitucionalidade das Leis. Agosto 2018, 120 páginas, Dissertação de Mestrado, Faculdade de Direito, Universidade de São Paulo, São Paulo, 2018.

Inicialmente, a presunção de constitucionalidade das leis estabelecia que a inconstitucionalidade de uma lei apenas poderia ser declarada quando se manifestasse "para além de qualquer dúvida razoável". Contudo, em virtude de novas teorias a respeito do papel do controle judicial de constitucionalidade na promoção da constituição, a presunção transformou-se e passou a admitir diferentes orientações (constitucionalidade e inconstitucionalidade) e diferentes forças (forte, média, fraca, etc.). Esse novo quadro, em constante evolução no âmbito da doutrina e da jurisprudência dos EUA, leva à necessidade de repensar o papel e conceito das presunções que atuam no controle de constitucionalidade - não só nos EUA, mas também nos diferentes sistemas constitucionais. Assim, através de uma metodologia de análise conceitual, a presente dissertação busca construir um conceito das presunções sobre a constitucionalidade no âmbito da teoria geral do direito constitucional (capítulo 1). A partir das diferentes formas com que presunções são empregadas pela jurisprudência (em especial da Suprema Corte dos EUA) e doutrina constitucionais (capítulo 2), argumenta-se que as presunções sobre a constitucionalidade são presunções legais relativas, isto é, estão previstas nas constituições e podem ser superadas (capítulo 3). Defende-se, ademais, que elas têm por funções principais estabelecer um nível de certeza para que uma determinada alegação sobre a constitucionalidade possa ser justificada ou negada, oferecer uma regra de decisão quando a presunção não é superada e distribuir o ônus de prova da constitucionalidade (capítulo 4). Por último, explora-se as diferentes justificativas possíveis para a força e orientação das presunções, argumentando que podem ser fundamentadas em justificativas indutivo-probabilísticas, procedimentais e, principalmente, considerações valorativas.

Palavras-chave: presunção de constitucionalidade; presunção de inconstitucionalidade; autocontenção; ativismo; deferência. 



\section{ABSTRACT}

TOMMASINI, Nicola. The Presumption of Constitutionality and Unconstitutionality of Laws. August 2018, 120 pages, Master Dissertation, Faculty of Law, University of São Paulo, São Paulo, 2018.

Initially, the presumption of constitutionality sought to limit the powers of judicial review by establishing that statutes could only be held unconstitutional if their incompatibility with the Constitution was "beyond all reasonable doubt". However, prompted by new theories on the role of judicial review, the presumption changed and began admitting different orientations (constitutionality and unconstitutionality) as well as different strengths (strong, medium, weak, etc.). This new role of presumptions in judicial review illustrates the necessity of a new concept of presumptions on constitutionality. Through conceptual analysis methodology, the present dissertation aims to contribute to this reconstruction by developing the concept of presumptions on constitutionality as a concept pertaining to the general theory of constitutional law (chapter 1). By exploring the different ways in which presumption are applied by doctrine and constitutional jurisprudence (especially the United States Supreme Court) (chapter 2), it first describes these presumptions as rebuttable presumptions which are establish by each particular constitution (chapter 3 ). Then, it argues that presumptions establish levels of certainty that authorize certain claims of constitutionality to be justified or unjustified (depending on the orientation of the presumption), erects decision rules for when a presumption is not successfully rebutted and allocates burdens of proof (chapter 4). Furthermore, it posits that presumptions can be based upon the following justifications: inductive-probabilistic, procedural and, most importantly, value considerations (chapter 5).

Key-words: presumption of constitutionality; presumption of unconstitutionality; self-restraint; activism; deference. 



\section{SUMÁRIO}

Capítulo 1 - Introdução.....................................................................15

$1.1 \mathrm{O}$ problema......................................................................... 15

1.2 Objetivo de pesquisa: construção de um conceito comum a

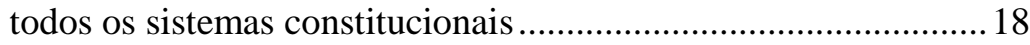

1.3 Recortes de pesquisa ................................................................ 19

1.3.1 Presunções "sobre" a constitucionalidade das leis ......... 19

1.3.2 Dois sentidos de presunção de constitucionalidade: entre a vedação ao descumprimento de lei não declarada inconstitucional e a regulação da atuação judicial

1.3.3 Presunção de constitucionalidade das leis e presunção de validade dos demais atos estatais ..........................................22

1.3.4 Aspectos subjetivos das presunções sobre a constitucio-

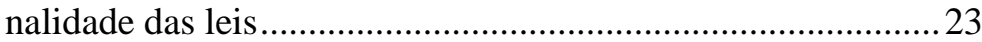

1.4 Pressupostos do trabalho .......................................................... 24

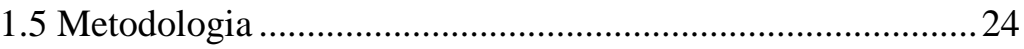

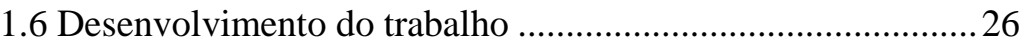

Capítulo 2 - Tranformações e aplicações das presunções sobre a constitucionalidade..................................................................28

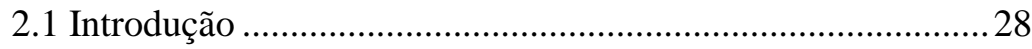

2.2 Transformações das presunções sobre a constitucionalidade

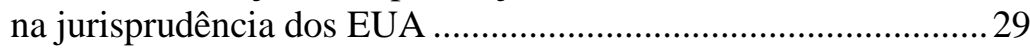

2.2.1 O modelo de Hamilton e o germe da presunção de constitucionalidade

2.2.2 O controle de constitucionalidade antes de Marbury v.

Madison

2.2.3 O início do controle de constitucionalidade da Suprema Corte (1803-1895) e a presunção forte de constitucionalida de 
2.2.4 A presunção de inconstitucionalidade das intervenções estatais no mercado (1897-1937) ..............................................34

2.2.5 A volta da presunção de constitucionalidade e a doutrina das posições preferenciais (1937-1953)......................37

2.2.6 A construção de níveis de intensidade de controle a partir das presunções sobre a constitucionalidade (1953presente)

2.2.6.1 A Corte Warren, a doutrina dos "direitos fundamentais" e o sistema de controle bifurcado ..........................41

2.2.6.2 Desenvolvendo o controle por níveis .....................44

2.3 Aplicações doutrinárias das presunções sobre a constitucionalidade 45

2.3.1 James Bradley Thayer e a presunção forte de constitu-

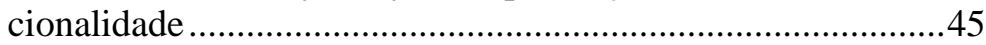

2.3.2 Randy Barnett e a presunção de liberdade .....................50

2.4 Aplicações das presunções sobre a constitucionalidade algumas lições ...

\section{Capítulo 3 - O que são as presunções sobre a} constitucionalidade?

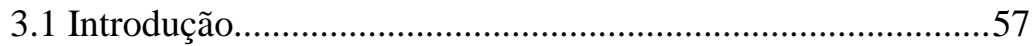

3.2 Presunções como antecipações de resultado ..........................58

3.3 Concepções de presunção e as presunções sobre a constitucionalidade

3.3.1 Concepção unitária de presunções (ou presunções como inferências)...

3.3.2 Concepção plural de presunções (ou análise conceitual de presunções a partir de seus diferentes tipos) ......................63

3.3.2.1 Presunções judiciais ou simples ..............................64

3.3.2.2 Presunções legais absolutas ....................................64

3.3.2.3 Presunções legais relativas ......................................65 
3.4 Presunções sobre a constitucionalidade como presunções

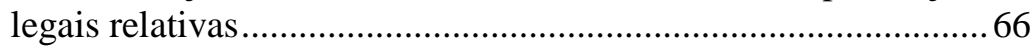

3.4.1 A previsão "legal” das presunções sobre a constitucionalidade 66

3.4.2 A relatividade das presunções sobre a constitucionalidade 68

3.5 A força das presunções 69

$3.6 \mathrm{O}$ objeto das presunções e a comprovação da constitucionalidade..... 70

3.6.1 Questões de direito como questões de fato.................... 72

3.6.1.1 Equivalência ontológica ...................................... 72

3.6.1.2 Equivalência epistemológica ................................ 74

3.6.2 Questões constitucionais e o âmbito de aplicação das presunções .75

\section{Capítulo 4 - Funções das presunções no controle de} constitucionalidade

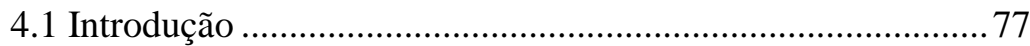

4.2 Incertezas e controle de constitucionalidade ......................... 77

4.2.1 Incertezas sobre a constitucionalidade.......................... 78

4.2.2 Incerteza, justificação e presunções.............................. 79

4.2.3 A possibilidade de indeterminação e a solução pela

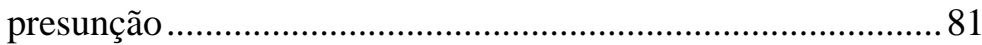

4.3 As funções das presunções sobre a constitucionalidade ........85

4.3.1 Níveis de certeza da constitucionalidade e intensidade

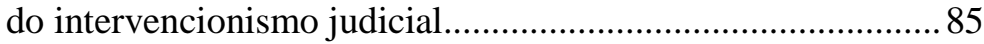

4.3.2 Regras de decisão: o benefício da dúvida da constitu-

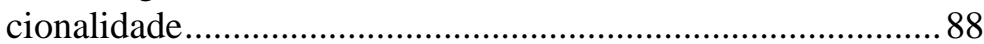

4.3.3 Ônus de provas nas questões constitucionais ................. 90 
Capítulo 5 - Justificando a orientação e força das presunções sobre a constitucionalidade ................................................................96

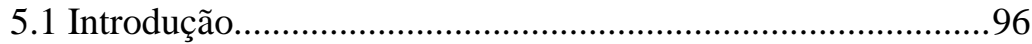

5.2 Concepções de presunções e justificativas ...............................96

5.3 Presunções e teoria do erro......................................................98

5.4 Como presunções podem ser justificadas.................................100

5.4.1 Justificativa indutivo-probabilística..................................100

5.4.2 Justificativa procedimental ............................................... 101

5.4.3 Justificativa valorativa ...................................................... 103

5.4.3.1 Democracia............................................................. 104

5.4.3.2 Direitos fundamentais...............................................107

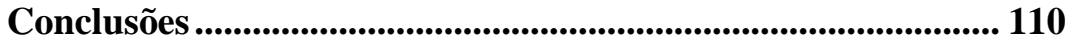

Lista de figuras e quadros.................................................................. 112

Referências .................................................................................. 114 


\section{CAPÍTULO 1 - INTRODUÇÃO}

\subsection{O problema}

O constitucionalismo, ao elevar certas normas jurídicas a nível hierárquico superior, apresenta-se em alguma medida como contraditório em relação à democracia (enquanto método de tomada de decisão majoritário $)^{1}$. Afinal, o empreendimento constitucional pretende justamente regular e limitar, material e formalmente, o poder decisório das maiorias constituídas. Essa contradição torna-se ainda mais expressiva quando o poder de fiscalizar esses limites é atribuído, ao menos em parte, a juízes constitucionais ${ }^{2}$. Sim, porque entrega poder de veto às decisões majoritárias a um órgão composto de membros que, em geral, não possuem mandatos eletivos e não respondem politicamente por suas decisões ${ }^{3}$.

É nesse contexto que floresceu, primeiramente nos EUA (com o adicional ingrediente de que o poder de controlar a constitucionalidade dos atos não figura expressamente na Constituição estadunidense), as chamadas "técnicas de autocontenção judicial”, que buscavam limitar as situações em que os juízes constitucionais poderiam legitimamente anular as decisões do parlamento.

\footnotetext{
${ }^{1}$ Ver BICKEL, Alexander. The Least Dangerous Branch. New York: Bobbs-Merrill, 1962 (discutindo a existência de uma "dificuldade contra-majoritária").

${ }^{2}$ Utiliza-se a expressão "juízes constitucionais" neste trabalho para se referir a membros do Poder Judiciário ou de uma Corte Constitucional responsáveis por controlar a constitucionalidade das leis.

3 "Existe uma tensão dialética que concerne à natureza do judicial review que causou com que sua aceitação fosse tentativa. O judicial review é antidemocrático por natureza; ele aloca uma autoridade incrível nas mãos de um grupo relativamente pequeno de pessoas que são virtualmente independentes e não responsabilizados pelo eleitorado" (SHAMAN, Jeffrey. The Rule of Reasonableness in Constitutional Adjudication. Hastings Constitutional Law Quarterly, vol. 2, 1975, p. 154. No original: "There is a dialectical tension concerning the nature of judicial review which has caused its acceptance to be quite tentative. Judicial review is undemocratic in nature; it places an awesome authority in the hands of a relatively small body of persons who are virtually independent from and unaccountable to the electorate").
} 
Dentre essas diferentes técnicas, figurou inicialmente ${ }^{4}$ nas decisões judiciais a chamada "presunção de constitucionalidade das leis", que condicionava a declaração de inconstitucionalidade "a uma violação clara e inequívoca da Constituição" (aqui denominada "regra da inconstitucionalidade flagrante"). A partir dela, impunha-se a necessidade de uma ampla e generalizada autocontenção judicial, a partir da qual a pronúncia de inconstitucionalidade deveria se restringir aos casos nos quais a incompatibilidade estaria "fora de qualquer dúvida razoável". Permitia-se, enfim, amplo espaço de atuação para o legislador.

Contudo, essa "regra da inconstitucionalidade flagrante" foi aos poucos sendo abandonada em favor de novas teorias sobre o papel dos juízes constitucionais nos sistemas democráticos, teorias essas que viam razões para um intervencionismo mais acentuado das Cortes ${ }^{6}$. Consequentemente, a ideia de uma "presunção de constitucionalidade" também passou por expressivas transformações, em especial no século XX. Iniciou-se um longo e complexo processo de flexibilização jurisprudencial e doutrinária dessa presunção, com o intuito de desvinculá-la do padrão instituído pela "regra de inconstitucionalidade flagrante".

Em pelo menos dois âmbitos diversos pode-se constatar claramente essa evolução:

a) $\mathrm{Na}$ Suprema Corte dos EUA, a Corte superou a "regra da inconstitucionalidade flagrante" no início do século XX, consolidando, aos poucos, entendimento de que as presunções no controle de constitucionalidade admitem diferentes forças

\footnotetext{
${ }^{4}$ Uma forma simplificada da presunção de constitucionalidade já pode ser observada na primeira declaração judicial de inconstitucionalidade reportada nos Estados Unidos: em 1793, no caso Kemper v. Hawkins, a Corte Geral da Virginia negou aplicação a uma lei, asseverando, quanto ao escopo do seu poder, que "a violação [à Constituição] deve ser evidente e clara, ou pode haver o perigo do Judiciário prevenir a operação de leis que podem produzir o interesse público". Para mais detalhes desse histórico, ver TREANOR, William Michael. Judicial Review Before Marbury. Stanford Law Review, vol. 58, 2005. Ver, também, tópico 2.2.

${ }^{5}$ Cooper v. Telfair, 1800, p. 171. Outras decisões, com descrição detalhada, em THAYER, James Bradley. The Origin and Scope of the American Doctrine of Constitutional Law. Harvard Law Review, v. VII, n. 3, 1893.

${ }^{6}$ Ver, no âmbito dos Estados Unidos, POSNER, Richard A. The Rise and Fall of Judicial SelfRestraint. California Law Review, vol. 100, n.3, junho 2012, pp. 519-596.
} 
(presunções fortes, fracas e médias) e orientações (presunções de constitucionalidade ou de inconstitucionalidade) ${ }^{7}$. Em outras palavras, a Corte oscilou, historicamente, entre períodos de maior e menor intervencionismo judicial, tendo, para tanto, flexibilizado aquela original presunção de constitucionalidade.

b) Na doutrina constitucional mais especializada, presunções sobre a constitucionalidade têm sido utilizadas para delinear o escopo do poder dos juízes constitucionais, seja por teorias mais ou menos intervencionistas ${ }^{8}$. Isso ocorre tanto para argumentos que defendem uma intensidade de controle própria para certas situações ou leis específicas (por exemplo, o direito de privacidade das mulheres determina que juízes devem ser poucos deferentes com a leis proibitivas do aborto, de modo que deve as presumir inconstitucionais), quanto para teorias normativas da atuação judicial que pretendem oferecer uma diretriz generalizante (por exemplo, o controle agressivo causa o abandono da interpretação constitucional pelo legislativo, razão pela qual o Judiciário deve sempre ser deferente e presumir fortemente a constitucionalidade das leis ${ }^{9}$ ).

Por isso tudo, a "presunção de constitucionalidade" assume hoje contornos muito mais amplos do que seu original sentido de restringir o controle judicial de constitucionalidade à "regra da inconstitucionalidade flagrante". Como esses exemplos bem demonstram, se presunções podem ter diferentes foças e orientações, podem também ser utilizadas tanto por cortes "ativistas" ticam a "deferência" ou "autocontenção" por isso, que presunções buscam delimitar o escopo da atuação judicial, e não se relacionam necessariamente com a deferência.

\footnotetext{
${ }^{7}$ Ver capítulo 2 para maiores desenvolvimentos.

${ }^{8}$ Ver tópico 2.3 para exposição de diferentes usos das presunções sobre a constitucionalidade em trabalhos doutrinários.

${ }^{9}$ Ver THAYER, James Bradley. The Origin and Scope of the American Doctrine of Constitutional Law. Harvard Law Review, v. VII, n. 3, 1893 e tópico 2.3.1.

${ }^{10}$ Ver, por exemplo, uso das presunções pela Era Lochner e Corte Warren, nos tópicos 2.2.4 e 2.2.6.1.

${ }^{11}$ Ver, por exemplo, uso das presunções antes de Marbury vs. Madison, no tópico 2.2.2.
} 
Apesar disso tudo, é curioso notar que quase nenhum trabalho buscou uma análise conceitual profunda das presunções sobre a constitucionalidade $^{12}$. Em verdade, muitos conceitos doutrinários ainda insistem na relação das presunções com a "regra da inconstitucionalidade flagrante", afirmando que "toda presunção é pela constitucionalidade da lei e toda dúvida razoável deve resolver-se em favor dela" 13 . É por isso e diante desse complexo contexto que o presente estudo pretende conceituar as presunções sobre a constitucionalidade e verificar qual suas funções no controle de constitucionalidade.

\subsection{Objetivo de pesquisa: construção de um conceito comum a to- dos os sistemas constitucionais}

A presunção de constitucionalidade aparece elencada, na jurisprudência e na doutrina constitucional, entre os postulados fundamentais do controle de constitucionalidade em boa parte dos sistemas constitucionais ocidentais, geralmente no contexto das limitações ao exercício judicial desse poder ${ }^{14}$. Trata-se de figura absolutamente tradicional que, desde o início do século XIX, se dissemina pelo mundo e, embora menos citada hoje do que outrora, resiste à crescente complexização do controle de constitucionalidade. Nesse sentido, "na grande maioria dos Estados democráticos do mundo vige o princípio da presunção de constitucionalidade da lei(...). As normas de nível legislativo estão, portanto, assistidas dessa presunção" ${ }^{15}$.

\footnotetext{
${ }^{12} \mathrm{O}$ esforço mais sistemático é de COMELLA, Victor Ferreres. Justicia Constitucional y democracia. Madrid: Centro de Estudios Constitucionales, 1997.

${ }^{13}$ BITTENCOURT, Lúcio. O controle jurisdicional de constitucionalidade das leis. Rio de Janeiro: Forense, $2^{\text {a }}$ ed., 1968, p. 82.

${ }^{14}$ Apenas exemplificativamente: no Brasil, ver BARROSO, Luís Roberto. Curso de Direito Constitucional Contemporâneo, São Paulo: Saraiva, $2^{a}$ ed., 2010, p. 301; na Espanha, ver COMELLA, Victor Ferreres. Justicia constitucional y democracia, Madrid: Centro de Estudios Constitucionales, 1997; nos Estados Unidos, ver Capítulo 2; na Índia, ver decisão da Suprema Corte em Namit Sharmia v. Union of India, 2012 ("A base de julgar (...) deveria ser a) que existe uma presunção de constitucionalidade; b) que o ônus de prova pertence àquele que peticiona $\mathrm{e}$ questiona a constitucionalidade das provisões". No original: "The basis of judging (...) should be a) there is a presumption of constitutionality; b) the burden of proof is upon the writ petitioners, the person questioning the constitutionality of the provisions");

${ }^{15}$ CARBONELL, Miguel. ¿Son Constitucionales las Iniciativas del Presidente?, Metapolítica, n. 60, 2008, p. 73 apud GARCÍA-MANSILLA, Manuel José. ¿Presunción de constitucionalidad o presunción de libertad? Un análisis desde el artículo 33 de la constitución nacional. Anales de 18
} 
Como se verá, as presunções sobre a constitucionalidade atendem a necessidades de todos os sistemas constitucionais que praticam o controle de constitucionalidade, quais sejam, de adotar um instrumento que informe qual o grau de certeza necessário para considerar uma lei constitucional ou inconstitucional e de informar como decidir diante da possibilidade de indeterminação, além de distribuir, em alguns casos, o ônus de prova entre os litigantes. Assim, a questão transborda as fronteiras jurídicas de um ou outro ordenamento, demandando um tratamento mais amplo que vise discernir o papel das presunções no controle de constitucionalidade de modo geral.

Diante disso, faz-se necessário buscar um conceito comum a todos os sistemas constitucionais, que abstraia tanto quanto possível as diferentes peculiaridades de cada ordenamento. Objetiva-se, enfim, a construção de um conceito das presunções sobre a constitucionalidade no nível da Teoria Geral do Direito Constitucional. As considerações aqui tecidas, portanto, tem a pretensão de aplicar-se a todos sistemas constitucionais que praticam o controle de constitucionalidade.

\subsection{Recortes de pesquisa}

\subsubsection{Presunções "sobre" a constitucionalidade das leis}

Muito embora a doutrina mais tradicional reconheça apenas uma presunção de constitucionalidade, não raro ouve-se também falar numa presunção de inconstitucionalidade ${ }^{16}$, especialmente no contexto de leis que interferem em direitos fundamentais. Como se trata, na verdade, de dois lados de uma mesma moeda, propõe-se o estudo das "presunções sobre a constitucionalidade": com isso, indica-se apenas que essas presunções dizem respeito à compatibilidade da lei com

la academia nacional de ciencias morales y políticas, 2014, p. 8. No original: "en la gran mayoría de los Estados democráticos del mundo rige el principio de presunción de constitucionalidad de la ley. [...] Las normas de rango legislativo están, por tanto, asistidas de esa presunción. Esto significa que a quien le incumbe la carga de la prueba es a quienes sostienen la inconstitucionalidad y no al revés".

${ }^{16}$ Ver análise de COMELLA, Victor Ferreres. Justicia Constitucional y democracia. Madrid: Centro de Estudios Constitucionalies, 1997. Para outros exemplos, em especial na jurisprudência e doutrina dos EUA, ver capítulo 2. 
a Constituição, podendo essa compatibilidade ser positiva (constitucionalidade) ou negativa (inconstitucionalidade) ${ }^{17}$.

Essa substituição, aliás, tem razões mais profundas de ser. Restringir, conceitualmente, as presunções a uma presunção de constitucionalidade pode não ser aconselhável diante da variedade de sistemas constitucionais hoje em vigor. Sim, porque é teoricamente possível que certas Constituições exijam uma postura mais ativa dos juízes e que, nesses casos, seja necessário presumir a inconstitucionalidade das leis ${ }^{18}$, deslocando o ônus de prova da constitucionalidade para o Estado ${ }^{19}$. Aliás, algumas Cortes - como a própria Suprema Corte dos Estados Unidos - já reconhece em alguns casos uma presunção de inconstitucionalidade.

Daí porque, no afã de construir um conceito comum a todos os sistemas constitucionais (ou pertencente à Teoria Geral do Direito Constitucional), torna-se necessário ampliar a expressão mais tradicional, substituindo-a pela expressão "presunções sobre a constitucionalidade".

1.3.2 Dois sentidos de presunção de constitucionalidade: entre a vedação ao descumprimento de lei não declarada inconstitucional e a regulação da atuação judicial

A presunção de constitucionalidade admite, na doutrina em especial, dois significados diversos: no primeiro sentido, a presunção de constitucionalidade estabelece uma vedação ao descumprimento de leis enquanto não declaradas inconstitucionais pelo Poder Judiciário; no segundo sentido, a presunção de constitucionalidade (e às vezes de inconstitucionalidade) busca regular a atuação judicial, estabelecendo

\footnotetext{
${ }^{17}$ Ainda assim, optou-se por manter o título do trabalho como "presunção de constitucionalidade e inconstitucionalidade das leis", dado que são esses os termos tradicionalmente utilizados. Uma modificação muito expressiva aqui poderia prejudicar a indexação do trabalho e dificultar seu acesso.

${ }^{18}$ Ver exemplos no capítulo 2.

${ }^{19}$ Ver, por exemplo, construção teórica de Randy Barnett sobre a Constituição dos EUA (BARNETT, Randy. Restoring the Lost Constitution: The Presumption of Liberty. Nova Jersey: Princeton University Press, 2004).
}

20 
critérios para a declaração de constitucionalidade ou inconstitucionalidade.

Quanto ao primeiro sentido, a antecipação da constitucionalidade tem relação com a exigibilidade da lei. A lei não pode, em síntese, ser descumprida por mera suspeita de inconstitucionalidade, razão pela qual ninguém se escusa observância da mesma até que declarada inconstitucional por um juiz constitucional ${ }^{20}$. A partir do momento, no entanto, em que um juiz declara a inconstitucionalidade da lei e estende a essa decisão os efeitos da nulidade ou anulabilidade, a presunção é superada e a lei se torna inexigível (ao menos em relação aos alcançados pela decisão) por razões de inconstitucionalidade.

Não obstante a evidente importância desse primeiro sentido de "presunção", o presente trabalho pretende a exploração do segundo sentido de presunções sobre a constitucionalidade, isto é, como instrumental que regula a atuação dos juízes quando da análise da constitucionalidade.

Aliás, tratar essas duas "presunções" sob uma mesma expressão é enormemente prejudicial à compreensão e desenvolvimento dos dois temas: além de frequentes confusões, é comum não ser possível identificar exatamente qual sentido de "presunção de constitucionalidade" está sendo utilizado quando da menção do termo em trabalhos acadêmicos e decisões judiciais.

Esse imbróglio conceitual se faz sentir, especialmente, quando se busca discernir quais prescrições - supostamente atribuídas a uma "presunção de constitucionalidade" - derivam do primeiro sentido e quais derivam do segundo. Para os fins do presente trabalho, bastará elencar aquelas prescrições que tem relação com o segundo sentido e que serão objeto da dissertação, quais sejam: os padrões de prova da constitucionalidade e inconstitucionalidade (tais como a regra da inconstitucionalidade manifesta), as prescrições de soluções de dúvidas sobre a constitucionalidade (in dubio pro legislatore e in dubio pro

${ }^{20}$ Cf. por todos, BARROSO, Luís Roberto. Curso de Direito Constitucional Contemporâneo. São Paulo: Saraiva, 2012, p. 301. 
libertate) e a distribuição do ônus de prova ou argumentação entre os litigantes constitucionais.

1.3.3 Presunção de constitucionalidade das leis e presunção de validade dos demais atos estatais

O presente objeto de estudo se insere, ademais, no âmbito das investigações da presunção de validade dos atos estatais. Afinal, a presunção de constitucionalidade não deixa de ser a presunção de validade de um tipo de ato estatal (a lei). No entanto, pretende-se, aqui, apenas a análise da presunção de constitucionalidade (ou compatibilidade com a Constituição) das leis (em sentido estrito, ou seja, enquanto ato emanado do Poder Legislativo com características de generalidade e abstração).

Esse recorte se justifica por considerações de ordem prática. Como adiante ficará claro, não há, a rigor, diferenças significativas entre as presunções sobre a constitucionalidade e outras presunções no Direito $^{21}$ - elas servem ao mesmo propósito e apresentam as mesmas características. No entanto, ao invés de explorar todo o grande universo de presunções aplicadas no Direito - tarefa essa, aliás, pouco produtiva - reduziu-se o escopo do trabalho às presunções sobre a constitucionalidade de modo a melhor compreender sua função no controle de constitucionalidade.

Também existem razões mais específicas para estudar apenas as presunções sobre a constitucionalidade. Em primeiro lugar, sofrem críticas específicas que devem ser individualmente avaliadas ${ }^{22}$. Em segundo lugar, apesar de um rico e complexo desenvolvimento jurisprudencial e doutrinário, poucos trabalhos até aqui efetivamente mergulharam numa análise conceitual profunda das presunções sobre a constitucionalidade, buscando pontuar suas principais características e apartá-la de outros institutos jurídicos. Daí porque parece imprescindível um olhar focado especificamente nelas.

\footnotetext{
${ }^{21}$ Ver capítulo 3, em que se explora a relação entre presunções e as presunções sobre a constitucionalidade.

${ }^{22}$ Idem.
} 
De toda forma, ainda que se trate de um tópico específico dentro do estudo maior das presunções em geral e das presunções de validade dos atos estatais, as presunções sobre a constitucionalidade parecem especialmente importantes porque impactam centralmente o princípio democrático, a separação de poderes e os limites da atuação judicial, razão que por si só justifica um exame particularizado.

\subsubsection{Aspectos subjetivos das presunções sobre a constitucionalidade das leis}

Estudos das presunções sobre a constitucionalidade estão geralmente atrelados ao Poder Judiciário. No entanto, como se verá, as presunções são necessárias sempre que uma decisão sobre a constitucionalidade da lei deve ser tomada, seja quem for o responsável por essa decisão (juízes, administradores, legisladores, etc.) ${ }^{23}$. Não se trata de instrumental exclusivamente disponível, portanto, aos juízes constitucionais.

Isso porque, como se pretende demonstrar adiante ${ }^{24}$, a presunção fornece dois elementos centrais para a decisão sobre a constitucionalidade: estabelece um padrão de prova e, em casos de possível indeterminação, uma regra de decisão ${ }^{25}$. Em outros termos, ela desempenha o crucial e necessário papel de dizer quão fortes precisam ser os argumentos para que a inconstitucionalidade (no caso de uma presunção de constitucionalidade) ou constitucionalidade (no caso de uma presunção de inconstitucionalidade) possam ser comprovadas e permitem uma decisão caso não seja possível essa comprovação.

Todavia, a presunção que cada um desses intérpretes aplica pode ser diferente, a depender da teoria de base sobre como cada um desses atores deve decidir sobre a constitucionalidade. $\mathrm{O}$ grau de certeza da constitucionalidade que o legislador precisa ter não é

\footnotetext{
${ }^{23}$ Dado que a presunção atende a uma necessidade epistemológica do processo de comprovação da constitucionalidade, qualquer órgão ou mesmo pessoa que se dispor a comprovar a constitucionalidade de uma norma deve adotar uma presunção. Ver mais a respeito no capítulo 4.

${ }^{24}$ Ver capítulo 4.

${ }^{25}$ Idem.
} 
necessariamente o mesmo que os juízes, e assim por diante ${ }^{26}$. Mas o que muda, nesse caso, é qual a presunção aplicável, e não se uma presunção é aplicável, ou seja, em ambos a presunções figura como elemento central do controle de constitucionalidade.

Essa distinção é relevante e impacta profundamente o controle de constitucionalidade pelos diferentes intérpretes constitucionais. Contudo, para fins de clareza de exposição principalmente, utiliza-se ao longo do trabalho os juízes constitucionais como locus de aplicação dessas presunções. Além de viabilizar o aspecto empírico do trabalho, essa perspectiva é vantajosa porque se insere num espaço onde é mais comum exigir-se (pelo menos por parte de juristas) certo rigor argumentativo. Mas é certo que a análise poderia (e deveria) se estender também para os demais atores responsáveis por decidir sobre a constitucionalidade.

\subsection{Pressupostos do trabalho}

O presente trabalho adota apenas dois pressupostos: alguma forma de separação de poderes e a possibilidade da declaração judicial de inconstitucionalidade. O conceito geral aqui construído, portanto, tem a pretensão de aplicar-se a qualquer ordenamento constitucional que autoriza o controle de constitucionalidade por juízes constitucionais e que distribui minimamente as funções de legislar e julgar entre diferentes órgãos. São pressupostos de fato bastante amplos, mas que não podem ser detalhados sob pena de deslocar o trabalho do âmbito da teoria geral do direito constitucional.

\subsection{Metodologia}

A presente dissertação utiliza de uma metodologia de análise conceitual, na medida em que pretende descrever as características fundamentais das presunções sobre a constitucionalidade e sua relação com outros institutos jurídicos ${ }^{27}$. Com isso, "quando analisamos um

\footnotetext{
${ }^{26}$ Ver especialmente as considerações de James Bradley Thayer, detalhadas no tópico 2.3.1.

${ }^{27}$ Nesse sentido, a pesquisa de análise conceitual pode ser descrita como "uma atividade na qual conceitos, suas características e relações com outros conceitos são esclarecidos". NUOPPONEN, 
conceito, nós o desmembramos em constituintes mais simples de modo a mostrar sua estrutura lógica e dar a ela uma explicação de seu conteúdo que transcende, mas incorpora, seu sentido léxico ordinário" 28 .

No específico caso das presunções sobre a constitucionalidade, a pesquisa conceitual justifica-se se não só pela utilidade de classificação e esclarecimento do conceito $^{29}$, mas também em razão da complexidade da técnica e o desconhecimento quase geral sobre suas particularidades.

Nesse sentido, com a delimitação do objeto, uma das melhores formas de prosseguir com a conceituação é investigando de que formas o termo estudado é empregado no ramo em que se insere. Tratase do aspecto empírico ${ }^{30}$ em que se baseiam as análises conceituais, que permite "teorizar a respeito de diferentes visões, buscando identificar compromissos filosóficos que elas implicam ou pressupõe, bem como princípios mais gerais que as explicam" 31 . Para tanto, dois foram os recortes de pesquisa dessa primeira etapa: em primeiro lugar, examinou-se como as presunções foram e são utilizadas pelo Poder Judiciário estadunidense, com foco especial na sua Suprema Corte. Esse enfoque se justifica na medida em que é nos EUA que se sugere e

Anita. Methods of concept analysis - a comparative study, LSP Journal, Vol.1, No.1, 2010, p. 4. No original: "as an activity where concepts, their characteristics and relations to other concepts are clarified”. Ver, também, HIMMA, Kenneth Eimar. Conceptual Jurisprudence: An Introduction to Conceptual Analysis and Methodology in Legal Theory, Revus, vol. 26, 2015, p. 66. No original:"General, or conceptual jurisprudence is concerned with giving what is called a "conceptual analysis' of core legal concepts; that is, conceptual jurisprudence is concerned with explicating the core concepts of our legal practices, including the interrelations among them" (grifou-se).

${ }^{28}$ HIMMA, Kenneth Eimar. Op. cit. p. 47. No original: "The idea is that when we analyze a concept, we break it down into simpler constituents so as to display its logical structure and give an explanation of its content that transcends, but incorporates, its ordinary lexical meaning - an idea that is quite common historically".

${ }^{29}$ HIMMA, Kenneth Eimar. Op. cit. p. 67

${ }^{30}$ SCHAUER, Frederick. "(Re)taking Hart. Harvard Law Review, 2006, p. 119: “a análise conceitual (...) inevitavelmente se baseia em parte em observações empíricas". No original: "Conceptual analysis(...) inevitably rests at least in part on empirical observation".

${ }^{31}$ HIMMA, Kenneth Eimar. Op. cit, p. 70. No original: "attempts to theorize these views by identifying deeper philosophical commitments they imply or presuppose, as well as more general principles that explain them". É exatamente nesta media, inclusive, que a ciência da lexicografia se diferencia da análise conceitual. 
aplica, pela primeira vez, uma "presunção de constitucionalidade das leis". Também, é na Corte Suprema que essa presunção passa por significativas transformações, modificando decisivamente algumas de suas características mais marcantes.

Em segundo lugar, estudou-se as diferentes aplicações de presunções sobre a constitucionalidade em obras doutrinárias específicas. Escolheu-se obras conhecidas por utilizarem especificamente das presunções para regulação dos juízes no controle de constitucionalidade. Destacam-se, nesse âmbito, os trabalhos de James Bradley Thayer e Randy Barnett.

Depois disso tudo, foi possível enxergar os pontos que ligam todas essas diferentes presunções, de modo a propor então um conceito, próprio da teoria geral, para as "presunções sobre a constitucionalidade". Nesse sentido, primeiro estudou-se o conceito de "presunções" na expressão "presunções sobre a constitucionalidade" para verificar se o termo é empregado de forma semelhantes em outras áreas do direito. Visto que, diferentemente do que se pensa, as presunções sobre a constitucionalidade são presunções jurídicas como quaisquer outras, as funções que cumprem são também as mesmas. Assim, investigou-se as funções das presunções em geral e como essas funções poderiam ser transpostas para o controle de constitucionalidade.

\subsection{Desenvolvimento do trabalho}

O presente trabalho é fruto de longo processo de investigação, que se inicia ainda na Iniciação Científica, realizada no âmbito da Pontifícia Universidade Católica de São Paulo (PUC-SP, financiada pela FAPESP ${ }^{32}$ ). Naquele projeto, intitulado "O escrutínio estrito e a possibilidade de sua aplicação no Brasil: graduando o princípio da presunção de constitucionalidade", a pesquisa buscava, a partir de uma perspectiva comparada, entender as diferenças entre o tratamento do tema pelo Brasil e pelos EUA.

\footnotetext{
${ }^{32}$ Processo n. 2014/27356-2, Fundação de Amparo à Pesquisa do Estado de São Paulo (FAPESP). 
Essa primeira etapa, embora bastante preliminar, foi essencial, sobretudo para o diagnóstico geral (que é confirmada por este trabalho) de que a presunção de constitucionalidade merece maiores desenvolvimentos conceituais. Despertou, assim, para a necessidade de estudos mais aprofundados e contextualizados do tema.

Por oportunidade do ingresso no Mestrado da Faculdade de Direito da Universidade de São Paulo (FDUSP, também financiada pela FAPESP ${ }^{33}$ ), agora sob orientação do Prof. Dr. José Levi Mello do Amaral Jr., teve-se ocasião de enfrentar a presunção de constitucionalidade de uma perspectiva mais abstrata, ampla e sistemática - enquanto conceito da Teoria Geral do Direito Constitucional - sendo também mais abrangentes as perguntas de pesquisas em relação ao trabalho realizado anteriormente. Trata-se de projeto realizado em diferentes instituições e que contou com a colaboração de muitos amigos e colegas que se dedicam ao estudo do direito constitucional.

${ }^{33}$ Processo n. 2017/07907-2, Fundação de Amparo à Pesquisa do Estado de São Paulo (FAPESP). 


\section{CONCLUSÕES}

De maneira geral, o presente trabalho buscou demonstrar que presunções sobre a constitucionalidade:

1) são presunções legais relativas, isto é, antecipam o resultado da constitucionalidade com certa força e provisoriamente a partir de uma previsão inscrita na constituição;

2) tem por funções: (2.1) estabelecer o nível de certeza necessário para superar a presunção, regulando a intensidade da atuação judicial; (2.2) fornecer regras de decisão nos casos de não-superação, considerando a possibilidade epistemológica de indeterminação sobre a constitucionalidade; e (2.3) distribuir o ônus de prova, nos sistemas em que alguma responsabilidade pode ser atribuída às partes;

3) podem ser justificadas para minimizar a chance de erro sobre a declaração de constitucionalidade (justificativa probabilística e procedimental) ou para evitar os erros mais graves (justificativa valorativa).

É importante ressaltar que essa construção não é normativa. Não se pretendeu, com ela, defender um determinado nível de intensidade da atuação judicial. O objetivo do presente trabalho foi bem mais singelo: demonstrar o que são essas presunções sobre a constitucionalidade, porque é necessário adotar alguma presunção no controle de constitucionalidade e demonstrar quais as possiveis formas de justificar forças e orientações específicas de presunções.

Desse modo, o único pressuposto propriamente normativo da construção é a racionalidade: percorre as ideias do texto que decisões sobre a constitucionalidade, para serem racionais, dependem em alguma medida dessas presunções. Isso porque se não se sabe o nível total de certeza necessário para declarar a constitucionalidade ou inconstitucionalidade de uma lei, decisões de constitucionalidade ou inconstitucionalidade são eminentemente arbitrárias e incontroláveis. $\mathrm{Na}$ há razão, enfim, por detrás de decisões que admitem e valoram argumentos, mas, ao final, não estabelecem qual a força que esses argumentos devem apresentar para justificar uma ou outra conclusão. 
Além disso, as presunções sobre a constitucionalidade demandam que juízes sejam honestos a respeito de incertezas na avaliação da constitucionalidade e, mais do que isso, que busquem as melhores respostas diante de inúmeras limitações (de tempo, de provas e até mesmo cognitivas). Situar a constitucionalidade no âmbito da epistemologia, nesse sentido, exige a construção de modelos teóricos nãoideais, que levem em consideração essas limitações dos juízes, sem deles exigir o que simplesmente não é factível.

De outro lado, espera-se também ter desvinculado as presunções de determinados ordenamentos jurídicos e demonstrado que se trata de instrumento fundamentalmente necessário em qualquer jurisdição constitucional que pretende tomar decisões racionais sobre a constitucionalidade das leis. A construção aqui de teoria geral pretende apenas servir como base conceitual para um refinamento dessas presunções no âmbito de cada ordenamento.

Disso se extrai, ademais, que é preciso não relacionar a figura das presunções com os EUA ou com fórmulas específicas de a autocontenção judicial (como, por exemplo, a regra da inconstitucionalidade flagrante). Muito pelo contrário, como já parece empiricamente comprovado, presunções podem concretizar posições mais ou menos intervencionistas, a depender de sua orientação e força.

Por último, cabe ressaltar que o tema das presunções é pouco desenvolvido no âmbito teórico, apesar de sua rica história jurisprudencial nos EUA. Longe de exaurir o tópico, o presente trabalho buscou ao menos alertar para sua relevância e a importância de maiores aprofundamentos. 


\section{LISTA DE FIGURAS E QUADROS}

Figura 1 - Concepção unitária de presunções (ou presunções como inferências)

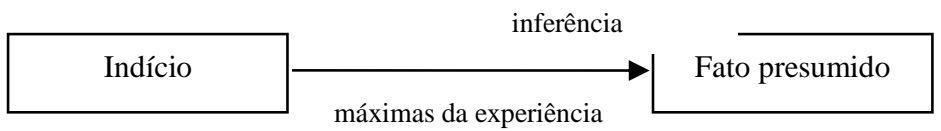

Figura 2 - Intensidade atuação judicial e presunções sobre a constitucionalidade

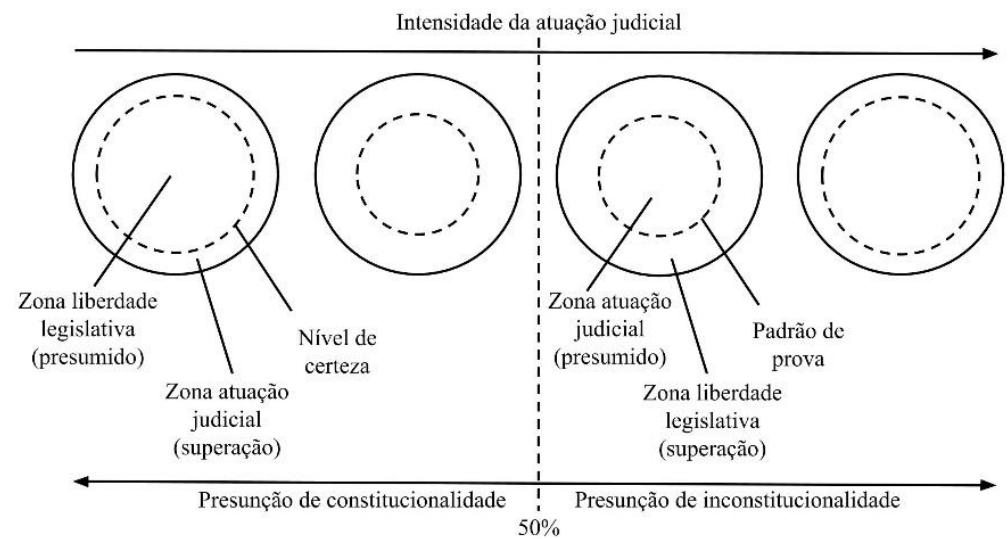

Quadro 1 - Combinações de justificação

\begin{tabular}{|c|c|c|c|}
\hline Alegação & Presunção & Presume-se & Se superada \\
\hline Constitucional & Constitucional & Justificada & Injustificada \\
\hline Constitucional & Inconstitucional & Injustificada & Justificada \\
\hline Inconstitucional & Constitucional & Injustificada & Justificada \\
\hline Inconstitucional & Inconstitucional & Justificada & Injustificada \\
\hline
\end{tabular}


Quadro 2 - Exemplo de constitucionalidade indeterminada

\begin{tabular}{|c|c|c|c|c|c|}
\hline Alegação & $\begin{array}{c}\text { Nível } \\
\text { certeza } \\
\text { Const. }\end{array}$ & $\begin{array}{c}\text { Nível } \\
\text { certeza } \\
\text { Inconst. }\end{array}$ & $\begin{array}{c}\text { Nível } \\
\text { certeza } \\
\text { Const. }\end{array}$ & $\begin{array}{c}\text { Nível } \\
\text { certeza } \\
\text { Inconst. }\end{array}$ & $\begin{array}{c}\text { Resultado epistemoló- } \\
\text { gico }\end{array}$ \\
\hline Const. & $60 \%$ & $40 \%$ & $70 \%$ & $50 \%$ & Indeterminado \\
\hline Const. & $60 \%$ & $40 \%$ & $60 \%$ & $50 \%$ & Constitucional \\
\hline Const. & $30 \%$ & $70 \%$ & $50 \%$ & $60 \%$ & Inconstitucional \\
\hline
\end{tabular}

Quadro 3 - Decisões sobre a constitucionalidade e resultados epistemológicos

\begin{tabular}{|c|c|c|c|}
\hline Presunção & Superação & Resultado epistemológico & Decisão \\
\hline \multirow[b]{2}{*}{ Const. } & Sim & Inconstitucional & Inconstitucional \\
\hline & Não & $\begin{array}{l}\text { Constitucional ou Indeter- } \\
\text { minada } \\
\text { (ou não-inconstitucional) }\end{array}$ & Constitucional \\
\hline \multirow[b]{2}{*}{ Inconst. } & Sim & Constitucional & Constitucional \\
\hline & Não & $\begin{array}{l}\text { Inconstitucional ou Indeter- } \\
\text { minada } \\
\text { (ou não-constitucional) }\end{array}$ & Inconstitucional \\
\hline
\end{tabular}




\section{REFERÊNCIAS}

ACKERMAN, Bruce. Beyond Carolene Products. Yale Law Review, vol. 98, n. 4, 1985, pp. 713-746.

ALEXANDER, Larry. Proving the Law: Not Proven. Northwestern University Law Review, vol. 86, n. 4, 1992, pp. 905-915.

ALEXY, Robert. Teoria dos Direitos Fundamentais. 2a ed. São Paulo: Malheiros, 2014.

AMARAL JÚNIOR, José Levi Mello. Incidente de Arguição de Inconstitucionalidade. São Paulo: Revista dos Tribunais, 2002.

BARNETT, Randy E. Foreword: The Ninth Amendment and Constitutional Legitimacy. Chicago-Kent Law Review, vol. 64, 1994, pp. 37-65.

BARNETT, Randy E. Foreword: The Power of Presumptions. Harvard Journal of Law \& Public Policy, vol. 17, n. 3, 1994, pp. 613625 .

BARNETT, Randy E. Restoring the Lost Constitution: The Presumption of Liberty, Princeton: Princeton University Press, 2004.

BARNETT, Randy E. Scrutiny Land. Michigan Law Review, vol. 106, junho 2008, pp. 1479-1500.

BARROSO, Luís Roberto. Curso de Direito Constitucional Contemporâneo. São Paulo: Saraiva, 2012.

BARROSO, Luís Roberto. O Controle de Constitucionalidade no Direito Brasileiro. 2a ed. São Paulo: Saraiva, 2006.

BICKEL, Alexander. The Least Dangerous Branch. New York: University Press, 1977.

BITTENCOURT, Lucio. O Contrôle Jurisdicional de Constitucionalidade de das Leis. Rio de Janeiro: Forense, 1968.

BONAVIDES, Paulo. Teoria Constitucional da Democracia Participativa, $3^{\mathrm{a}}$ ed. São Paulo: Malheiros, 2008.

BORK, Robert H. The Tempting of America. New York: Touchstone, 1991.

114 
BULOS, Uadi Lammêgo. Curso de Direito Constitucional. São Paulo: Saraiva, 2015.

CARBONELL, Miguel. ¿Son Constitucionales las Iniciativas del Presidente?, Metapolítica, n. 60, 2008.

CHEMERINSKY, Erwin. Constitutional Law: Principles and Policies. 2nd ed. New York: Aspen Publishers, 2002.

CLERMONT, Kevin M. Standards of Proof Revisited, Vermont Law Review, vol. 33, 2009, pp. 469-487.

CLERMONT, Kevin. A Comparative View of Standards of Proof. American Journal Of Comparative Law, vol. 50, 2002, pp. 243275.

CLÈVE, Clèmerson Merlin, LORENZETTO, Bruno Meneses. Constituição, Governo Democrático e Níveis de Intensidade do Controle Jurisdicional. Revista Jurídica Luso Brasileira, v. 2, p. 409-471, 2015.

CLÈVE, Clèmerson Merlin, LORENZETTO, Bruno Meneses. Constituição Federal, Controle Jurisdicional E Níveis De Escrutínio. Direitos Fundamentais \& Justiça, v. 9, p. 97-123, 2015.

COMELLA, Victor Ferreres. Justicia Constitucional y Democracia. Madrid: Estudos Constitucionales, 1997.

COOLEY, Thomas. Treatise Of Constitutional Law. $5^{\text {a }}$ ed., Boston: Little, Brown and Company, 1883.

COX, Archibald. The Warren Court. Cambridge: Unversity Press, 1979.

DIDIER JR, Fredie, BRAGA, Paulo de Sarna, OLIVEIRA, Rafael Alexandria. Curso de Direito Processual Civil, São Paulo: JusPodium, $9^{\mathrm{a}}$ ed., 2014.

DIMOULIS, Dimitri, LUNARDI, Soraya. A decisão do Supremo Tribunal Federal sobre a união de pessoas do mesmo sexo. In: ANJOS FILHO, Robério Nunes dos (org.). STF e Direitos Fundamentais, São Paulo: JusPodium, 2013. 
DIMOULIS, Dimitri, LUNARDI, Soraya. Curso de Processo Constitucional. $2^{\mathrm{a}}$ ed. São Paulo: Atlas, 2014.

ELY, John Hart. Democracia e Desconfiança. São Paulo: Martins Fontes, trad. Juliana Lemos, 2010.

FALLON JR., Richard H. Strict Judicial Scrutiny. UCLA Law Review, n. 54, 2007, pp. 1267-1335.

GABIN, Sanford Byron. Judicial Review, James Bradley Thayer, and the "Reasonable Doubt" Test. Hastings Constitutional Law Quarterly, vol. 3, 1976, pp. 961-1014.

GUNTHER, Gerald. Foreword: In Search of Evolving Doctrine on a Changing Court: A Model for a Newer Equal Protection. Harvard Law Review, vol. 86, n. 1, nov. 1972, pp. 1-48.

HAMILTON, Alexander. Federalist Papers. n. 78, 1787.

HAMILTON, Alexander. Federalist Papers, n. 81, 1787.

HAND, Learned. The Bill Of Rights. Cambridge: Harvard University Press, 1958.

HESSICK, F. Andrew. Rethinking the Presumption of Constitutionality? Notre Dame Law Review, vol. 85, 2010, pp. 1447-1504.

HIMMA, Kenneth Eimar. Conceptual Jurisprudence: An Introduction to Conceptual Analysis and Methodology in Legal Theory. Revus, vol. 26, 2015.

JACKSON, Vicki. TUSHNET, Mark. Comparative Constitutional Law, New York: Foundation Press, 1999.

JAIN, Tarun. Presumption of Constitutionality, Icafai University Publications. Ainda não publicado. Disponível em: http://papers.ssrn.com/sol3/papers.cfm?abstract_id=1087388

LAURENTIIS, Lucas de. Interpretação Conforme a Constituição: conceitos, técnicas e efeitos. São Paulo: Malheiros, 2012.

LAWSON, Gary. Evidence of The Law. Chicago: Chicago University Press, 2017. 
LAWSON, Gary. Proving The Law. Northwestern University Law Review, vol. 86, n. 4, 1992, pp. 859-904.

LEAL, Roger Stiefelmann. O Efeito Vinculante na Jurisdição Constitucional. São Paulo: Saraiva, 2006, p. 27.

LEYVA, Raymundo Gama. James Bradley Thayer, un precursor de la teoría las presunciones. Teoria Jurídica Contemporânea, vol. 1, jul.nov. 2016.

LEYVA. Raymundo Gama, Concepciones y Típologias de las presunciones em el derecho continental. Revista de Estudios de la Justicia, n. 9, 2013.

LUSKY, Louis. Footnote Redux: A Carolene Products Reminiscence. Columbia Law Review, vol. 22, 1982, p. 1092.

MASSEY, Calvin. The New Formalism: Requiem for Tiered Scrutiny? Journal of Constitutional Law, vol. 6, n. 5, maio 2004, pp. 945997.

MIRANDA, Jorge. Manual de Direito Constitucional. $3^{\text {a }}$ ed. Coimbra: Coimbra Editores, 1996.

MORGAN, Edmund M. Further Observations on Presumptions. Southern Carolina Law Review, vol. XVI, n. 4, junho 1943, pp. 245-265.

MORGAN, Edmund M. Some Observations on Presumptions. Harvard Law Review, n. 44, 1930-1931, pp. 906-934.

MORO, Sérgio Fernando. Legislação Suspeita. Afastamento da Presunção de Constitucionalidade das Leis. São Paulo: Juruá, 1999.

NANCE, Dale A. Civility and the Burden of Proof. Harvard Journal of Law \& Public Policy, vol. 17, n. 3, 1994, pp. 647-690.

NOTES. The Presumption Of Constitutionality. Columbia Law Review, vol. 31, n. 7, 1931, pp. 1136-1148.

NOWAK, John, ROTUNDA, Ronald. Constitutional Law. New York: West Group, 6th ed. 2000. 
NUOPPONEN, Anita. Methods of concept analysis - a comparative study, LSP Journal, Vol.1, No.1, 2010.

O’SHEA, John J. C.; SONDERICKER, William F. Presumptions of Constitutionality. Catholic University Law Review, vol. 2, 19511952, pp. 101-111.

POSNER, Richard. The Rise And Fall Of Judicial Self-Restraint. California Law Review, vol. 100, n. 3, junho 2012.

POWELL JR, Lewis F. Carolene Products Revisited. Columbia Law Review, vol. 82, n. 82, pp. 1088-1092.

RIVERS, Julian. Proportionality and Variable Intensity of Review; Cambridge Law Review, v. 65, n. 1, 2006.

SANTOS FERREIRA, William. Princípios Fundamentais da Prova Cível. São Paulo: Revista dos Tribunais, 2014.

SARMENTO, Daniel, SOUZA NETO, Cláudio Pereira da. Direito Constitucional. Teoria História e métodos de trabalho. 2a ed. Belo Horizonte: Fórum, 2014.

SCHAUER, Frederick. "(Re)taking Hart. Harvard Law Review, vol. 119, n. 3, 2006.

SHAMAN, Jeffery. Cracks In the Structure: The Coming Breakdown of Levels of Scrutiny. Ohio State Law Journal, v. 45, 1984, p. 161.

SHAMAN, Jeffrey. The Rule of Reasonableness in Constitutional Adjudication. Hastings Constitutional Law Quarterly, vol. 2, 1975

SIEGEL, Stephen A. The Origin of The Compelling State Interest Test and Strict Scrutiny. American Journal of Legal History, vol. 48, n. 4, 2006, pp. 355-407.

SILVA, José Afonso da. Teoria do Conhecimento Constitucional. São Paulo: Malheiros, 2014.

SNOWISS, Sylvia. Judicial Review and the Law of the Constitution, New Haven: Yale University Press, 1990. 
SOUZA NETO, Claudio Pereira, SARMENTO, Daniel. Direito Constitucional: Teoria, história e métodos de trabalho. Belo Horizonte: Fórum, 2015.

SWEET, Alec Stone, MATTHEWS, Jud. All Things in Proportion? American Rights Doctrine and the Problem of Balancing. Emory Law Review, vol. 60, 2011, pp. 101-180.

SWEET, Alec Stone. Proportionality Balancing and Global Constitutionalism. Columbia Journal of Transnational Law, vol. 72, 2008.

TAVARES, André Ramos, TOMMASINI, Nicola. Graduando a presunção de constitucionalidade. In: Revista Fórum Jurídico, v. 7, pp. 66-69.

TAVARES, André Ramos. Minorias e Justiça Constitucional. In: Revista Brasileira de Estudos Constitucionais - RBEC, ano 4, n. 13, jan./mar. 2010, pp. 13-33.

THAYER, James Bradley. The Origin and Scope of American Constitutional Doctrine. Harvard Law Review, v. VII, n. 3, 1893.

THAYER, James Bradley. A Preliminary Treatise On Evidence at Common Law. Boston: Little, Brown and Company, 1898.

TOMMASINI, Nicola; DIAS, Roberto. Reflexões críticas sobre a declaração de inconstitucionalidade de ofício. Revista de Investigações Constitucionais, Curitiba: Fórum, ago. 2018, no prelo.

TREANOR, William Michael. Judicial Review Before Marbury. Stanford Law Review, vol. 58, 2005.

TRIBE, Laurence H. The Puzzling Persistence of Process-Based Constitutional Theories. The Yale Law Journal, vol. 89, 1980, pp. 1063-1080.

TRIBE, Laurence H. American Constitutional Law. 2nd ed. New York: Foundational Press, 1998.

TUSHNET, Mark. Madison vs. Marbury Around the World. Tennessee Law Review, vol. 71, pp. 251-274. 
ULLMAN-MARGALIT, Edna. On Presumption. The Journal of Philosophy, vol. 80, n. 3, Mar. 1983, pp. 143-163.

VERMEULE, Adrian. Judicial Review and Institutional Choice. William \& Mary Law Review, vol. 43, n. 4, 2002, 1557-1567.

WINKLER, Adam. Fatal in Theory and Strict in Fact: An Empirical Analysis of Strict Scrutiny in The Federal Courts. Vanderbilt Law Review, vol. 59, 2006, pp. 793-871.

WOLFE, Christopher. The Rise of Modern Judicial Review, New York: Basic Books, 1986.

WRIGHT, Benjamin F. The Growth of American Constitutional Law, Chicago: University of Chicago Press, 1942.

YOUNG, Allison L. In Defence of Due Deference. The Modern Law Review, vol. 72, n. 4, 2009, pp. 554-580. 